\title{
Significados da escolarização para alunos da educação de jovens e adultos
}

\author{
Ellen Taline de Ramos' \\ Centro Universitário Nossa Senhora do Patrocínio, Itu - SP - Brasil \\ Claudia Stella \\ Universidade Presbiteriana Mackenzie, São Paulo - SP - Brasil
}

\begin{abstract}
Resumo: Este artigo visa apresentar a investigação do processo de retorno à escolarização de adultos a partir de seus significados para os alunos de EJA, compreendendo os motivos pelos quais voltaram à escola e o significado desta na vida adulta. Os alunos expressam em suas falas a desvalorização que atribuíam à educação quando criança e como o abandono dos estudos os afetou, pessoal e profissionalmente. Hoje, valorizam a educação por ser essencial para o mercado de trabalho, e não necessariamente pelo seu aprimoramento pessoal; o mesmo mundo do trabalho que tira as crianças da escola, para cuidarem de sua subsistência, exige um retorno do adulto trabalhador aos bancos escolares, para que possa continuar na cadeia produtiva e "superar" sua atual situação socioeconômica. Nota-se, também, a herança histórica da produção do abandono escolar, na qual aqueles de classes mais pobres carregam estigmas de uma suposta lacuna cultural perpassada pela exclusão e pelo preconceito.
\end{abstract}

Palavras-chave: educação de jovens e adultos; educação; história de vida; teoria crítica; fracasso escolar.

\section{MEANING OF SCHOOLING OF STUDENTS OF YOUTH AND ADULT EDUCATION}

\begin{abstract}
The objective of this work is to present the investigation done on the process of return to adults' school, using their meaning of schooling, understanding the reasons why students have returned to school and the meaning that the school acquired in theirs adulthood. We observed the devaluation of education as a child and realization of how the abandonment of studies have affected their lives, personal and professional, in addition, it was observed that nowadays, education is essential to the job market. The same labor market that took children out of school to take care of themselves, now requires of workers a return to school, so that they can continue in production chain and overcome (at least wishfully) your current socioeconomic status. We noticed also the historical heritage of producing dropout, in which those who come from the poorer classes carry stigmas of a supposed cultural gap throw exclusion and prejudice.
\end{abstract}

Keywords: youth and adults education; education; life history; critical theory; school failure.

\section{SIGNIFICADOS DE LA ESCOLARIZACIÓN DE LOS ESTUDIANTES DE LA EDUCACIÓN DE LOS JÓVENES Y ADULTOS}

Resumen: Este artículo propone presentar una investigación sobre el proceso de retorno a la escolarización de adultos desde los significados de la escolarización de los

1 Endereço para correspondência: Ellen Taline de Ramos, Centro Universitário Nossa Senhora do Patrocínio, Rua Jovita, 166, Santana - São Paulo - SP - Brasil. CEP: 02036-000. E-mail: ellentramos@gmail.com. 


\begin{abstract}
estudiantes, teniendo en cuenta los motivos por los cuales volvieron a la escuela y el significado de la misma en la vida adulta. Los alumnos expresan en sus discursos la desvalorización que atribuían a la educación cuando eran niños y cómo el abandono de los estudios afectó sus vidas, personales y profesionales, se observó también que hoy, valoran la educación por ser esencial para el mercado de trabajo, y no precisamente por perfeccionarse personalmente, el mismo mundo laboral que saca a los niños de las escuelas, para cuidar de la subsistencia, exige un regreso del adulto trabajador a los pupitres escolares, para que pueda continuar la cadena productiva y superar (al menos ilusoriamente) su actual situación socioeconómica. Nos damos cuenta también de la herencia histórica del abandono escolar, en la cual aquellos de clases más pobres cargan estigmas de una supuesta laguna cultural dejada por la exclusión y el prejuicio.
\end{abstract}

Palabras clave: educación de los jóvenes y adultos; educación; historia de vida; teoría crítica; fracaso escolar.

A procura de jovens e adultos pela educação tem aumentado significativamente ao longo dos anos (MEC/Inep, 2013). Seja por motivos pessoais ou profissionais, as pessoas que não tiveram a oportunidade de participar do processo de escolarização formal em idade apropriada voltam aos bancos escolares. Nesse sentido, o presente artigo é resultado de duas pesquisas, que tiveram o mesmo delineamento metodológico, realizadas com alunos da Educação de Jovens e Adultos (EJA) de ensino fundamental com histórico de evasão escolar e que reingressaram posteriormente à escola. Ambas as pesquisas tiveram como objetivo investigar o fracasso escolar a partir da história de vida escolar dos alunos da EJA identificando os motivos pelos quais os alunos saíram da escola, a que atribuía seu fracasso escolar, além da relação professor -aluno, a influência familiar, o posicionamento escolar, o motivo do retorno à escola e, por fim, a verificação dos conhecimentos adquiridos além do ensino formal. No entanto, a distinção entre as pesquisas se deu pelo fato de que em uma delas os participantes eram de uma escola pública e, na outra, os participantes eram de escola privada de ensino a distância.

O presente artigo visa realizar uma interseção entre algumas das informações provenientes de ambas as pesquisas, apontando alguns dos motivos e dos significados da escolarização na vida desses sujeitos e o porquê do seu retorno na vida adulta.

A educação de jovens e adultos está presente na história do Brasil desde os tempos coloniais, a princípio, sob responsabilidade dos religiosos/jesuítas que chegaram ao Brasil e criaram escolas para ensinar os índios, tendo como objetivo, além de catequizá-los, alfabetizá-los e, consequentemente, inseri-los na cultura europeia, numa tentativa clara de domesticação e submissão do índio adulto (Paiva, 2007). No entanto, até o direito à educação ser adquirido por todos, houve muitas reformas. No que diz respeito à Educação de Jovens e Adultos, as maiores mudanças começaram a ocorrer a partir da década de 1920 do século passado, época de grande avanço industrial, no qual a necessidade de mão de obra capacitada e formalmente educada promoveu o combate à alta taxa de analfabetismo; havia, também, naquele momento, questões de controle social, uma vez que a classe operária crescia nas grandes cidades e fazia uma grande pressão para que tivesse uma efetiva participação política. Diante disto, 
se estabeleceu a criação de escolas para adultos no período noturno (Brasil, 2002; Acosta \& Rego, 2006).

Muitas das mudanças ocorridas se intensificaram, principalmente no período da ditadura militar que, dentre outras coisas, modificou a educação, pautando-se supostamente nas ideias de Paulo Freire que em seu livro Pedagogia do Oprimido (1996), destaca e combate a ideia de uma educação bancária que considera o educando como um recipiente vazio, no qual o educador depositaria todo o seu conhecimento e o educando memorizaria e reproduziria ocupando assim um papel passivo. Em contraposição a isto, Freire propõe a educação libertadora, na qual o aluno passaria de passivo para ativo. Em outras palavras: ele seria considerado no processo educativo trazendo palavras geradoras que impulsionariam sua aprendizagem, durante a ditadura militar. Outro programa com a intenção de enfrentar o analfabetismo foi implementado: o Movimento Brasileiro de Alfabetização (Mobral); movimento contou com bons recursos e com vestígios da proposta que vinha se desenvolvendo desde o início dos anos 1960, porém, desprovidos de todo senso crítico, reflexivo e problematizador. Este programa difundiu-se por todo país até meados da década de 1980, sendo extinto em 1985 (Brasil, 2001).

Com o final da ditadura militar e com a possibilidade de uma maior amplitude política, difundiram-se pesquisas relacionadas à educação, enfatizando a relação da leitura e escrita, não apenas com o fato de ser alfabetizado, mas com a ideia orientada pela busca de significados de uma educação contextualizada, reforçando e retomando as críticas aos modelos de aprendizagem baseados em palavras soltas e frases isoladas, estimulando, assim, a ideia de uma educação pautada no que os indivíduos conheciam da língua e de suas experiências. Este conceito estendeu-se além da educação de crianças beneficiando os jovens e os adultos (Brasil, 2001).

Nos anos 1990, surge na atual Lei de Diretrizes e Bases da Educação (LDB), Lei n. 9.394/1996, uma seção específica para a EJA, reafirmando o direito já expresso na Constituição de 1988. Desse modo, a LDB garante uma educação voltada para as necessidades dos alunos adequando-se as suas rotinas cotidianas e ao contexto de suas trajetórias de vida. Como parte da Educação Básica, a EJA, tem como objetivo oferecer ao aluno formação indispensável para o exercício do trabalho e da cidadania (Brasil, 1996). Atualmente, de acordo com o Censo Escolar da Educação Básica (2013), há 3.102.816 de matrículas na EJA. Deste número, cerca de $69 \%$ encontram-se cursando o ensino fundamental, enquanto $31 \%$ estão no ensino médio, dado que indica que a maioria dos que estão na EJA encontram-se nas séries iniciais da Educação Básica. Além disso, é notório que a Educação de Jovens e Adultos vem adquirindo cada vez mais visibilidade, o que é demonstrado por meio dos dados históricos e pelo crescimento no número de matrículas nessa modalidade de ensino no decorrer dos anos, como explicitado no gráfico abaixo.

Por meio destes dados, nota-se que, a partir de 1996, ocorre um aumento gradativo na procura pelo retorno à escola, atingindo seu ápice de matrículas entre 2006 e 2008 
com aproximadamente 5 milhões de matriculados. Podemos inferir que este aumento se relaciona com as políticas educacionais pós-ditadura, desde a Constituição de 1988, que garantiu o acesso à educação para todos, até a LDB de 1996 que estabeleceu as diretrizes da educação nacional e demais diretrizes educacionais que contribuíram para a diminuição das taxas de analfabetismo e o aumento da escolaridade dos brasileiros.

\section{Gráfico I. Número de Matrícula na EJA}

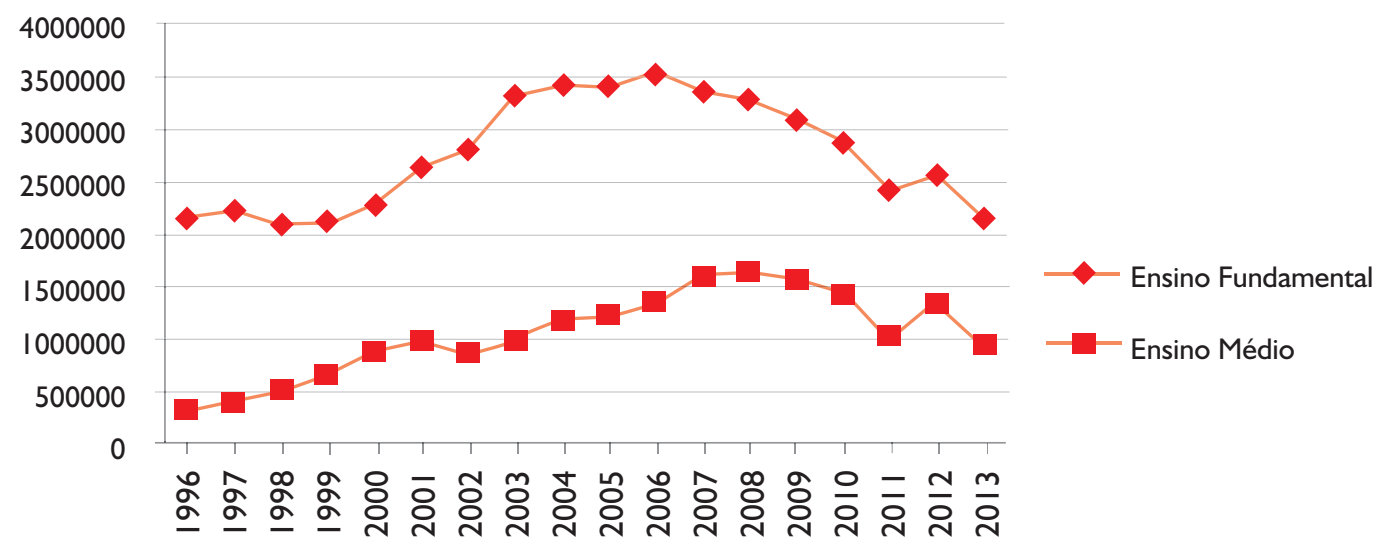

Ano

Fonte: Censo da Educação Básica (MEC/Inep), 2013.

Com fundamento neste breve retrospecto histórico, percebemos que as políticas educacionais brasileiras para jovens e adultos sempre estiveram voltadas para questões políticas e econômicas, servindo muitas vezes a um governo que, apoiado em bases capitalistas, precisava formar uma mão de obra que atendesse às necessidades do avanço econômico e tecnológico que invadiu o país ao longo da história. Contudo, a história também nos aponta a possibilidade de uma emancipação do indivíduo por meio da educação. O movimento promulgado por Paulo Freire é um exemplo concreto de uma educação contextualizada que promove a reflexão crítica do trabalhador e, consequentemente, sua possível conscientização social. Hoje este tipo de pedagogia é amplamente utilizado pelo Movimento dos Sem Terra (MST), que conseguiu construir seu próprio método, o qual valoriza a relação do homem com a terra, contextualizando-o em seu habitat e nas relações políticas com sua comunidade. Desta forma, considerando a importância da compreensão dos resquícios históricos na história de vida escolar de adultos em relação a sua trajetória educacional de abandono e retorno aos bancos escolares e os significados sociais nela colocados, as questões que nortearam este estudo foram: qual(ais) a(s) concepção(ões) do aluno a respeito de seu retorno à escola? Que aspectos o motivaram para a volta à escolarização? 
Para se responder a essas problemáticas, necessita-se compreender brevemente as ideias relacionadas ao fracasso escolar e à Teoria Crítica da Sociedade. Para compreender o fracasso escolar, é preciso contextualizar questões históricas, tais como a criação da escola como mecanismo necessário "à qualificação das classes populares para o trabalho que movia os setores primários e secundários da economia capitalista" (Patto, 2005, p. 42).

No entanto, os trabalhadores passavam pela profissionalização de forma exploratória, sendo exigido destes muitas horas de trabalho, sem descanso e com baixos salários. Assim, os trabalhadores enquanto "aprendiam" treinavam no próprio trabalho e, desse modo, a escola foi se desenvolvendo, como interesse principal da burguesia e da pequena nobreza europeia. Acreditava-se que a escola possuía grande poder de transformação da humanidade, pois atendia à elite de forma cultural e as classes trabalhadoras para a profissionalização da mão de obra. Entretanto, essa crença foi abalada pela Primeira Guerra, pois os homens perceberam que o conhecimento não os havia livrado da guerra, da desigualdade e da exploração. Em decorrência disto, iniciou-se a busca por uma nova pedagogia, que considerasse a promoção espiritual do ser humano (Patto, 2005).

O desenvolvimento dessa nova pedagogia trouxe com ela a crença de que a educação possibilitaria uma sociedade igualitária, na qual obter-se-iam lugares sociais com base em méritos pessoais. Mas isto não ocorreu, pois a educação, mesmo expandindose da burguesia para os trabalhadores, continuou com práticas elitizadas e preconceituosas com os mais pobres. Por causa disto, o fenômeno do fracasso escolar começou a povoar o cotidiano escolar (Patto, 2005). As primeiras perspectivas a respeito desse fenômeno, entre os séculos XVII e XIX, foram realizadas especialmente pelos psiquiatras que classificavam de maneira rígida os "anormais", conceito estendido dos hospícios para as escolas. Desta forma, "as crianças que não acompanhavam seus colegas na aprendizagem escolar passaram a ser designados como anormais escolares e as causas de seu fracasso são procuradas em alguma anormalidade orgânica" (Patto, 2005, p. 63). Assim, nos primeiros anos do século XX, a avaliação médica dos "anormais escolares" tornou-se sinônimo de avaliação intelectual e, consequentemente, os testes de QI ganharam grande importância nas decisões tomadas pelos educadores a respeito de para que escola e/ou sala encaminhar cada aluno.

Durante o percurso do entendimento do fracasso escolar, os resultados dos testes psicológicos apontavam resultados mais baixos em negros e trabalhadores pobres. Em virtude disso, a explicação para as dificuldades deixa de ser ligada ao biológico, e passa a ser cultural, o que traz um preconceito disfarçado e explicações para o determinismo a respeito da relação entre classe social e nível de escolaridade. Disto surge a "teoria da carência social", que tende a explicar, por preconceitos e estereótipos, o insucesso escolar, fato este que influenciou os textos da época que traziam a ideia de que "os adultos das classes subalternas são considerados mais agressivos, relapsos, desinteressados pelos filhos, inconstantes, viciados e imorais do que os das classes do- 
minantes" (Patto, 2005, p. 72). Diante disso, vê-se que nos estudos realizados a tendência à culpabilização do aluno por seu baixo desempenho, responsabilidade esta que no máximo é estendida à família sem se considerar as questões políticas, pedagógicas e sociais. No entanto, salienta-se que se deve mudar o olhar sobre o fenômeno do fracasso escolar e deixar de vê-lo como responsabilidade de um, ou outro, mas observá-lo de maneira multifacetária.

Entretanto, o discurso de culpabilização é tão forte que passa a ser reproduzido pelos próprios alunos, que interiorizam esses pressupostos e se autorresponsabilizam por sua dificuldade de aprendizagem (Asbahr \& Lopes, 2006), considerando a dificuldade existente como resultado da falta de esforço e de capacidade do aluno, desconsiderando a possibilidade de métodos pedagógicos falhos como é explicitado nos estudos de Asbahr e Lopes (2006) e de Ferreira, Assmar, Omar, Delgado, González, Silva, Souza, \& Cisne (2002). Esta questão de culpabilizar o aluno e/ou sua família pelo fracasso escolar, segundo Crochík (1997), é tão ideológica quanto a aplicação de testes e classificação dos alunos por meio destes, uma vez que, se há um espaço de relativa autonomia para a constituição do indivíduo e da família que aponta para uma certa distância da sociedade, sem esta os "alunos-problemas" não podem ser entendidos, pois não é possível se falar de indivíduo sem que se refira, necessariamente, à introjeção da cultura e, assim, quando a relação indivíduo-cultura não é considerada, fazendo com que se entenda o indivíduo em si mesmo, perde-se a tensão entre ambos (Crochík, 1997, pp. 19-20).

Em um estudo realizado em três países (Brasil, Argentina e México) sobre os motivos do fracasso ou sucesso escolar atribuídos pelos alunos, pôde-se notar que a maioria dos entrevistados revelou fatores internos como responsáveis por seu desempenho escolar. Em primeiro lugar, citaram desempenho e, em seguida, capacidade (Ferreira et al., 2002), ou seja, a ideia de responsabilizar o aluno por seu desempenho escolar é compartilhada pelo Brasil e por outros países.

Outro fator que aparece em vários estudos é que na visão dos professores o fracasso escolar da criança é decorrente de problemas de saúde (esfera biológica), ou seja, acreditam que se a criança não aprende é porque está com algum tipo de disfunção neurológica, distúrbios de aprendizagem, desnutrição etc. Diante dessa crença, os professores e a escola frequentemente realizam encaminhamentos das crianças a serviços de saúde (Collares \& Moysés, 1997; Patto, 2005) e, usualmente, "as opiniões acerca das causas do fracasso escolar são as mesmas; as propostas de solução são idênticas; os diagnósticos da professora confirmam-se pelos médicos, psicólogos, fonos... Todos exercendo mais a ação de rotulação do que de diagnóstico" (Collares \& Moysés, 1997, p. 146). Neste contexto, cabe à Psicologia intervir, não de forma tradicional, com uma visão psicologizante ou médica, mas sim de modo histórico-social, ou seja, procurando compreender o fenômeno, considerando não apenas o que o aluno não aprende, mas também suas relações familiares, escolares; em outras palavras, é necessário considerar a história de vida do sujeito, para que desta forma possa-se olhar o problema em sua totalidade e não de maneira fragmentada (Patto, 2005; Asbahr \& Lopes, 2006; Caldas, 2005). 
Pensando-se na escola e nos seus métodos de ensino, é possível notar que há incompatibilidade entre o que é ensinado ao aluno e o que é vivenciado por este cotidianamente. Por este motivo, muitos alunos sentem-se desmotivados, uma vez que a escola Ihes oferece algo desinteressante. Desta forma tende-se a atribuir o fracasso do aluno a ele e à inferioridade cultural do local de onde vem. As crianças pobres são vistas como malcriadas, rebeldes, doentes, sujas, vindas de famílias desestruturadas e desinteressadas, outro fator levantado por Caldas (2005). Como possível responsável pelo fracasso ou sucesso escolar do aluno é a relação existente entre esse e seu professor, o qual muitas vezes nutre expectativas positivas ou negativas a respeito de um aluno, que acaba influenciando-o em seu fracasso ou sucesso na vida acadêmica. Desta forma, podemos considerar o fracasso escolar "um problema de ordem institucional, político e pedagógico, cuja superação requer ações nesses campos" (Collares \& Moysés, 1997, p. 147) e não apenas na patologização e culpabilização do aluno.

Analisando todo o exposto a respeito do fracasso escolar e suas tendências, nota-se que os alunos que têm problemas de aprendizagem e, consequentemente, tiveram insucesso em seus estudos, apresentam consequências psicológicas que levam pela vida. Quando crianças frequentemente nutrem sentimentos de incapacidade, reconhecem-se como "burros", entre outras questões, que perpassam sua autoimagem. Essa desmotivação e desvalorização de si e, em contrapartida, a motivação para o sucesso escolar que as crianças apresentam, também podem ser vistas nos adultos da EJA. Baquero (2001), ao sugerir aos alunos a produção de um texto a respeito da importância da leitura, com o seguinte tema de redação: Minha vida sem saber ler e escrever, aplicado a jovens e adultos, notou nos resultados que muitos tinham dificuldades de leitura e escrita, mas em suas redações ressaltavam a ideia de desvalorização dos analfabetos, o que demonstra a reprodução de um imaginário social, construído historicamente, no qual o trabalho intelectual é mais bem qualificado em detrimento do manual. Tal concepção é expressa por frases como: "a gente sem estudo não somos nada nem ninguém; se eu não soubesse ler e escrever eu era um inútil para a vida" (Baquero, 2001, pp. 106-108).

Segundo Baquero (2001, p. 18), "ser analfabeto não significa apenas não saber ler e escrever; significa muito mais, significa, entre outras coisas, ser uma vergonha nacional, ser um bicho bruto qualquer, não ser ninguém. É por isso que até podemos, hoje, utilizar a palavra 'analfabeto' como uma ofensa". Pode-se notar neste trabalho, mediante a análise das informações obtidas, que os adultos participantes da pesquisa veem a alfabetização como algo essencial, pois é por meio da educação que se diferenciam do animal e caracterizam-se como humanos pertencentes ao social. Assim, em uma sociedade, na qual leitura e escrita são consideradas essenciais, a aprendizagem "é uma condição, um meio do falante se humanizar em uma sociedade letrada, ou não, mesmo que imaginariamente" (Baquero, 2001, p. 12).

No entanto, apesar da ideia arraigada em nossa cultura de que a educação traz a possibilidade de ascensão social, de fuga da marginalização e de saída do lugar de 
dominação para o de dominador, nota-se que essas questões não passam de ideologias, uma vez que se possibilita ao sujeito que sonhe e acredite nessas possibilidades, mesmo que não existam para a maioria da população. Desta forma, os indivíduos passam por um assujeitamento histórico na ilusão de que, por meio da aprendizagem, deixará o papel de marginal, fracassado ou bicho/coisa (Baquero, 2001).

Desta maneira, é importante que se reflita a respeito destas questões, visto que se vê que há possibilidades de mudanças, que vêm ocorrendo de forma gradual, desde que se olhe o fenômeno como um todo, considerando situações institucionais, métodos de ensino, compatibilidade de conteúdos estudados e conteúdos vividos pelos alunos, relação professor-aluno que muitas vezes pode contribuir para o insucesso escolar, ao ambiente familiar do aluno, a suas questões emocionais e biológicas, além de quaisquer outros fatores que podem estar envolvidos, ou relacionados ao cotidiano escolar, para que assim possa se ter maior clareza do fenômeno e intervenção adequada quando necessário. 0 outro ponto a ser levantado é a respeito da escola de Frankfurt. Nesta parte do texto, serão brevemente definidos e discutidos conceitos da Teoria Crítica da Sociedade sobre a educação e seus objetivos. Adorno começa a escrever sobre educação na década de 1950 e a concebeu como forma de combate à ideologia e "como instituição necessária ao combate à violência, como formadora de indivíduos autônomos, democráticos e emancipados, sem desconsiderar os limites desta sociedade" (Crochík, 2009, p. 16).

Entretanto, o próprio Adorno (1995) assume não ser pedagogo e que seus escritos têm como objetivo refletir acerca da formação cultural considerando-a como: aquela que dissesse respeito - de uma maneira pura como seu próprio espírito - ao indivíduo livre e radicado em sua própria consciência, ainda que não tivesse deixado de atuar na sociedade e sublimasse seus impulsos. A formação era tida como condição implícita a uma sociedade autônoma: quanto mais lúcido o singular, mais lúcido o todo (Adorno, 1996, p. 391).

Em decorrência dessa formulação, o autor discute a crise na formação cultural, uma vez que no lugar dela é difundida a semiformação ou semicultura socializada. Destaca que, apesar de toda informação disseminada e do acesso quase irrestrito à cultura por parte da parcela mais pauperizada da população, é a semiformação que passa a dominar a consciência. Para ele, formação é a apropriação subjetiva da cultura, a qual possui duplo caráter, pois, ao mesmo tempo, remete-se à sociedade e também realiza a mediação desta com a semiformação. Quando a cultura é compreendida como conformação, adaptação ao meio sem possibilidade de reflexão, os homens impedem-se de educarem uns aos outros, reproduzindo a semicultura (Adorno, 1996). Por outro lado, em uma sociedade dominada pela irracionalidade, concebe a educação com objetivo de desbarbarização, a qual deverá "orientar esses traços [derivados dos instintos] contra o princípio da barbárie, em vez de permitir seu curso em direção à desgraça" (Adorno, 1995, p. 158). É importante frisar que a barbárie se relaciona à regressão e, "continuará existindo enquanto persistirem no que têm de fundamental as condições que geram esta" (Adorno, 1995, p. 117). 
Dessa forma, Adorno traz a questão da necessidade de contrapor-se à ausência de consciência, por meio de uma educação autocrítica, para evitar "que as pessoas golpeiem para os lados sem refletir a respeito de si próprias" (Adorno, 1995, p. 121). Essa educação crítica para a desbarbarização seria facilitada desde que fosse feita a partir da primeira infância, momento em que se forma o caráter, por meio da dissolução de qualquer autoridade; todavia, isto seria inviável, "pois os pais com que temos que lidar são, por sua vez, também produtos desta cultura e são tão bárbaros como o desta cultura" (Adorno, 1995, p. 167).

Assim, para Adorno, trabalhar para a desbarbarização é a temática mais urgente da educação e para isso seria necessário um esclarecimento geral, que poderia evitar a repetição de Auschwitz, tratada pelo autor como a expressão máxima da barbárie. Fica evidente que a tarefa da educação e da escola não será realizada se o clima cultural também não for transformado, fato que se constitui como algo extremamente complexo, uma vez que, por um lado, seria necessário que o indivíduo compreendesse as contradições sociais, rompendo assim com as amarras da ideologia dominante e, por outro, que a sociedade rompesse com suas estruturas alienantes e opressoras. 0 grau de complexidade se dá, pois indivíduo e sociedade são indissociáveis. Sendo assim, para que a mudança ocorra, é necessário que essas duas categorias se tencionem e se alterem sucessivamente. Nesse sentido, uma educação para a emancipação poderia contribuir intensamente para esse processo.

\section{Método}

O estudo atual é resultado da junção de dois trabalhos: um com alunos do ensino público e outro com alunos do ensino privado. Ambos tiveram o mesmo delineamento metodológico: entrevistas com alunos da EJA de ensino fundamental com histórico de evasão escolar e que reingressaram tardiamente à escola. Para a coleta de dados, utilizou-se da metodologia de história de vida, no entanto, vale ressaltar que neste artigo serão utilizados apenas trechos de algumas dessas histórias.

O total de entrevistados nas duas pesquisas foi de nove pessoas sendo: seis alunos da EJA ensino fundamental de uma escola estadual, três do sexo masculino e três do sexo feminino, com idades de 18, 21, 22, 2342 e 45 anos. Destes entrevistados, apenas um era natural de São Paulo, enquanto dois eram do Maranhão, um do Ceará, um da Bahia e um de Minas Gerais. Três alunas da EJA de uma escola particular de ensino a distância, com idades de 20, 23 e 30 anos, todas nascidas na região nordeste, duas na Bahia e uma em Alagoas. Todos os participantes estudavam no município de São Paulo e vivenciaram a experiência de entrada e de evasão escolar na infância.

Para a coleta de dados, realizou-se levantamento, via internet, de escolas particulares e de escolas estaduais do município de São Paulo que possuíam EJA ensino fundamental. Posteriormente, a pesquisadora entrou em contato com as escolas via e-mail e/ou telefone, explicando brevemente os objetivos da pesquisa e questionando a possibilidade da realização desta na instituição. Em seguida a este primeiro contato, 
foi marcada reunião com os responsáveis pelas escolas para o detalhamento das pesquisas e para a assinatura da Carta de Informação à Instituição juntamente com o Termo de Consentimento Livre Esclarecido. Depois das autorizações das escolas, falouse com os alunos da EJA de maneira coletiva na sala de aula, para convite e explicação da pesquisa aos alunos. Depois da anuência de alguns estudantes, agendaram-se locais e data para a realização das entrevistas que foram realizadas por meio de entrevista, áudios gravados com duração média de 25 minutos, que continham uma questão norteadora: como foi sua história escolar? E a partir desta e de acordo com a necessidade e do desenrolar de cada entrevista, acrescentaram-se outras questões, a fim de direcionar a entrevista e obter informações significativas. As entrevistas foram realizadas posteriormente à aprovação do Comitê de Ética e os participantes foram escolhidos em decorrência de sua história escolar de entrada e de evasão escolar na infância e se deu depois da assinatura do Termo de Consentimento Livre Esclarecido que seguia todas as determinações para pesquisas realizadas com seres humanos.

Depois da realização das entrevistas, estas foram transcritas literalmente, respeitando a linguagem dos participantes, e submetidas à análise do conteúdo, para investigação dos significados das palavras (Bardin, 2000).

\section{Educação tardia: (re)significados (im)possíveis}

Considerando o ser humano com um ser sócio-histórico, passível de construções e reconstruções durante o dinamismo da vida, é possível notar diante de diversos estudos que o processo educativo se constitui como algo considerado essencial para o reconhecimento subjetivo da humanidade, pois há, no imaginário social, a perspectiva de que só é visto aquele que detém conhecimento, só há possibilidades de ascensão para o escolarizado. Há na vida cotidiana a ideia de desvalorização dos analfabetos, o que demonstra a reprodução desse imaginário social, construído historicamente, no qual o trabalho intelectual é melhor qualificado em detrimento do manual. Tal concepção é expressa, muitas vezes, por frases que minimizam as capacidades daqueles que não detêm o letramento (Baquero, 2001), como verificamos nas falas de nossos entrevistados. Para Vargas e Gomes (2013, p. 452), ao retornar para a escola "os conceitos construídos ao longo da vida passam por um processo de transformação e ressignificação, estabelecendo uma nova relação cognitiva que resulta no desenvolvimento subsequente da consciência e de vários processos internos do pensamento, além da reconstrução de conceitos".

Pode-se verificar, por meio dos estudos realizados, que os alunos da EJA tendem a ver a alfabetização como algo essencial, pois é por meio da educação que se diferenciam do animal e caracterizam-se como humanos pertencentes ao social e são reconhecidos como cidadãos de direitos e então "visíveis" ao mundo. Muitas vezes, os alunos enfrentam dificuldades financeiras e de subsídios para ir à escola, mas há algo que os move e os motiva a continuar: a "sede de aprender"; "a busca de uma vida melhor"; o "exemplo para os filhos"; o "reconhecimento social" (Baquero, 2001, Vargas \& Gomes, 2014). 
Foi possível notar nas falas dos entrevistados tanto do presente estudo como de outros estudos, já citados, que as trajetórias de vida de alunos da EJA são semelhantes: há a inserção na escola na idade correta e, por motivos de desinteresse, a falta de incentivo/proibições de parentes, a distância da escola, as necessidades financeiras e a entrada no mercado de trabalho precocemente, que levam os indivíduos à evasão escolar e a uma vivência que intercala e atropela diversas fases da vida desses alunos evadidos. Assim o que se vê é que "as memórias da escola se entrelaçam com as memórias da infância e estas com as memórias do trabalho" (Pereira, 2012, p. 19). Além disso, não podemos deixar de considerar, assim como debatido por alguns autores que discutem o fracasso escolar, que essa dificuldade ou falta de acesso de determinada parcela da população à escolarização diz respeito a processos discriminatórios e desiguais provenientes do processo histórico de acesso aos processos educacionais em nosso país. Ao olharmos para esse estudo e para os sujeitos participantes, isso aparece de maneira evidente, pois os entrevistados são prioritariamente advindos de estados do Nordeste, local onde é clara a dificuldade de acesso a diversos direitos. A intersecção das diversas áreas da vida pode ser exemplificada pela fala de Diana (30 anos) ao se referir ao motivo de seu retorno ao meio educacional:

O que me fez voltar? É que nem eu falei, falemos assim, como eu trabalho numa Rotisserie né, então eu num tenho assim um estudo suficiente pra trabalha. Pra mim entra no colégio, uma que eu quero sai de lá, pra mim é assim, encontra, tipo um trabalho melhor, eu tenho que ter estudo e isso eu num tenho. [...] então eu to procurando, caminhando pra estuda pra vê se eu consigo alguma coisa, pretendo assim, faze faculdade num sei. Só por causa do trabalho mesmo e é bom porque a gente se diverte também um pouco.

Na fala de Diana, fica clara sua confusão entre as áreas da vida e sua perspectiva de um futuro melhor que a move em direção dos estudos, todavia, o que fica evidente é a possível valorização de sua escolaridade no mundo do trabalho, o que possibilitaria uma "vida melhor", colaborando com a política dominante de que só se vale alguma coisa quando se distancia da população iletrada e se toma lugar em um mundo capitalista. Por um lado, apesar da ideia arraigada em nossa cultura de que: a educação traz a possibilidade de ascensão social, de fuga da marginalização e de saída do lugar de dominação para o de dominador, nota-se que essas questões não passam de reproduções ideológicas, uma vez que possibilita ao sujeito que sonhe e acredite nessas possibilidades, mesmo que não existam para a maioria da população, como exemplificado na fala acima. Desta forma, os indivíduos passam por um assujeitamento histórico na ilusão de que por meio da aprendizagem deixará o papel de marginal. Por outro lado, ao examinar as histórias de vida dos alunos e alunas entrevistados, foi possível verificar que há uma esperança que os move e que os direciona em sentido à escolarização, fato que subjetivamente gera significados e contribui para o reconhecimento do indivíduo como ser empoderado do saber, o que possibilita alterações em sua autopercepção, como explicita Líbia (45 anos), uma de nossas entrevistadas: 
Você tem que progredir, procurar pessoas que possa te ajudar. [...] Nos estudos te dar uma orientação, te informa [...] isso é importante pra ter um futuro melhor. [...] O estudo é ótimo, porque o estudo você se realiza em todos os sentidos, se você busca, batalha, você consegue. [...] Leio muito, muito. Peguei uns livros de séries diferentes, já li uns três, é legal, eu gosto. É um bom conhecimento, a memória funciona, é bom para o teu corpo. Tudo que faz bem para o corpo você tem que continua, é isso.

Diante do explicitado entusiasticamente por Líbia, é possível visualizar a valorização da cultura letrada e, além disso, pode-se visualizar em sua fala um impacto que evidencia a experiência de vivenciar a EJA como um local que apresenta uma série de possibilidades educativas que lhe dá acesso a diversos tipos de conhecimentos. Seu desejo pelo conhecimento amplia a importância da educação em sua vida depois de anos fora da escola, e se estende para fora do âmbito cognitivo, atingindo sua subjetividade também em uma esfera corporal. Além disso, sua fala expressa de maneira interessante a ideia, enraizada cada vez mais em nossa sociedade, da semiformação, uma vez que o acesso à leitura e sua realização parece ocorrer de maneira irrefletida, pois sua ideia geral ainda está presa à ideia de "progredir na vida" no sentido de que, para progredir, é imprescindível estudar para dessa maneira possuir maior possibilidade de "um futuro melhor". No entanto, o que se considera um futuro melhor em nossa sociedade? Um emprego com status? Ganhar muito dinheiro? Para responder a essas questões, precisamos pensar que, assim como discutido por Adorno (1995), para se alcançar a formação, é necessário um esforço individual. Entretanto, não se deve responsabilizar apenas o indivíduo que "fracassa", pois não se pode esquecer de que este se constitui como sujeito sócio-histórico em uma sociedade pautada pelas desigualdades de acesso a direito historicamente construídos. Sendo assim, em decorrência da classe social a qual se pertence, o acesso aos serviços não será o mesmo para toda população, não sendo possível então falar-se em meritocracia e em uma formação cultural se não trabalharmos para reduzir as desigualdades sociais e econômicas.

Considerando o processo de entrada e evasão dos alunos da EJA, pode-se perceber que estes são influenciados por esse processo histórico, que criou e cristalizou diferenças sociais e culturais que são permeadas de preconceitos, pela culpabilização do aluno. Tomando o estudante como responsável por suas próprias dificuldades, reforça-se a crença de que este possui um problema biológico por meio da patologização do fracasso escolar ou, ainda, problemas psicológicos e familiares, principalmente das famílias mais pobres, entre outros fatores que os influenciaram em seu processo de evasão escolar. Todavia, para além dessas questões, vemos alunos empenhados em tentar retomar seus estudos e "fazer diferente", gerando significados muitas vezes atrelados a projeções familiares e expectativas depositadas neles, fato que pode fazer com que rompam com a lógica da exclusão, retomando assim o processo educativo, como pode ser visto na fala de Maurício (28 anos):

O estudo é a base de tudo né, e assim na minha família mesmo, o único que não seguiu os estudos mesmo, fui eu, as minhas irmãs, uma, são todas pedagogas, o outro é biólogo e os outros estão se 
dando bem em relação aos estudos. E eu vejo que é preciso estuda, em primeiro lugar, pra se ter conhecimento, que é uma coisa que ninguém rouba de ti né! Que ninguém rouba de ti! O segundo ponto é que o mercado de trabalho que nós vivemos exige muito, exige muito. E também... tem o lado sentimental, eu tenho que dar essa alegria pro meu pai, eu tenho que um dia... é faze alguma coisa de útil da vida e... pra fazer essa coisa útil, só mesmo através dos estudos.

É interessante notar a relevância dada à educação socialmente e que esta extrapola para o âmbito familiar contribuindo para a alta expectativa dos pais de Maurício e, consequentemente, para sua autocobrança. Todavia, visualiza-se também a afetividade que perpassa a possibilidade de término dos estudos, tanto para sua realização pessoal, quanto para a realização familiar. Outro ponto ressaltado pelo entrevistado é a questão do trabalho que aparece nas falas da maior parte dos entrevistados. Quanto a isto, vê-se que há uma lógica escola/trabalho, na qual a relação estabelecida é quanto maior o número de anos estudados maiores possibilidades de trabalho e, por conseguinte, melhores postos trabalhos. Entretanto, essa lógica mostra-se falha, pois a possibilidade de ascensão, quando ocorre, é para uma minoria. Mas, movidos por esta essa ideia, muitos alunos retornam à escolarização. Outra questão interessante é a ideia de que é somente via educação que se pode fazer "algo útil", o que ressalta mais uma vez a perspectiva de exaltação da educação como forma de subjetivação e reconhecimento social. Um outro ponto de vista possível a respeito da educação é o oferecido pela Teoria Crítica da Sociedade. Adorno considera a educação como forma possível de combate à ideologia e à violência. Todavia, ao conversarmos com alunos da EJA pôde-se notar que a violência perpassa o cotidiano escolar, como Líbia explicita em seu discurso:

Ai nós estávamos lá [sala de aula] e o rapaz, eu não vou citar nome do aluno, foi pegar a chave na diretoria, quando ele voltou [...] ai vem três caras [...] veio pra dá um soco no garoto da classe. Entraram dentro da classe, jogaram 3 cadeiras, quase me acertaram, e a moça do lado, eu fiquei com o sistema de... o meu sistema abalado, fiquei chorando a aula inteira [...] o rapaz veio, tento agredi o garoto, ameaço de matá-lo [...] Aí escuta só, aí eu peguei, o cara começou, voltou na sala e falo assim ó: (fez sinal de arma com a mão) que ia detona o rapaz, mas o rapaz já tinha ido embora, a polícia acompanhou sei lá. Agora você acha, pra que essa violência?

Diante dessa fala, cabe questionarmos: será que a violência presente no cotidiano escolar influencia os demais alunos? Será que esse fator pode motivá-lo a deixar a escola? Por um lado, acredita-se que sim, pois a própria entrevistada citou que ficou "com o sistema abalado", mas, por outro, vemos que esse movimento não a influencia a ponto de desestimulá-la, pois como ela demonstra em suas falas sempre gostou da escola, mas foi afastada desta por motivo de trabalho e é este mesmo trabalho que agora a motiva a retornar. No entanto, é possível que em outros casos ou se essa violência se propagar cotidianamente haja o desestímulo e uma nova evasão. Além disso, 
a violência que povoa o cotidiano escolar pode estar diretamente relacionada com a ideia de semiformação, pois, por causa de sua propagação, a sociedade "forma" indivíduos cada vez mais individualistas e alienados, fato que contribui para a não identificação com o outro e, consequentemente, com a propagação de relações coisificadas, o que pode influenciar o aumento da violência, pois se não vejo o outro como meu semelhante agredi-lo é algo naturalizado. Nesse sentido, caminhamos em direção à barbárie e esquece-se de que "agem em contradição com seus próprios interesses imediatos, são assassinas de si mesmas na medida em que assassinam ou outros" (Adorno, 1995, p. 137).

É inegável que os alunos da EJA, ao adquirirem conhecimento escolar, sentem-se importantes e reconhecidos como seres humanos e, o mais importante, reconhecemse a si próprios como sujeitos de direitos. A educação ainda que precária é uma via de acesso ou possibilidade de acesso a uma parcela dessa cultura. Diante dessa afirmação, cabe ressaltar que não é porque já há um acesso restrito à educação que se precisa se conformar com isso e deixar de pensar e refletir sobre a vivência escolar, muito pelo contrário, é reconhecendo que o que é aprendido pelos alunos contribui para sua constituição subjetiva e para a transformação social, que se deve cada vez mais pensar as políticas públicas igualitárias voltadas para a educação, não só na infância como na formação continuada de jovens e adultos, bem como na superação de suas defasagens educacionais, uma vez que a organização escolar e a disposição de recursos pedagógicos também influenciam nos processos de desinteresse e evasão; e para além disso pensar uma educação que possa caminhar para a reflexão e não apenas uma educação para o ajustamento e conformação dos indivíduos à sociedade ou ao mercado de trabalho, resquícios de um processo histórico ainda tão presente nos dias atuais. Dessa maneira, vale retomar a leitura de Adorno, na qual concebe a educação com objetivo de desbarbarização e é pelo reconhecimento do cotidiano e pelas pequenas desbarbarizações diárias que se pode aos poucos chegar em uma "educação reflexiva a qual deverá orientar os instintos violentos, contra o princípio da barbárie, em vez de permitir seu curso em direção à desgraça" (Adorno, 1995, p. 158).

A educação, para o autor, tem como objetivo evitar a barbárie e/ou suas representações, entre elas, a citada por Líbia e educar o homem para sua emancipação, possibilitando a este compreender as contradições presentes em seu cotidiano. Pode-se considerar que uma tentativa de desbarbarização ocorre quando Líbia, ao final de sua fala citada acima, questiona o porquê da violência, uma vez que por causa de uma situação corriqueira há uma ameaça à vida de outra pessoa. Assim, infere-se que, ao mesmo tempo que se apresentam no cotidiano escolar possibilidades de rompimento da violência, por outro lado, há uma negligência em relação às violências escolares, pois na situação explicitada pela participante não há nenhum tipo de intervenção institucional sobre o ocorrido, fato que indica que o esclarecimento geral pontuado por Adorno (1995) não ocorre, permitindo assim a produção e reprodução de atos violentos. Contudo, para ele, a barbárie possui uma razão objetiva, decorrente da 
cultura e da própria sociedade, visto que dividiu os homens em trabalhadores físicos e intelectuais, subtraindo assim a confiança em si e na cultura, fato explicitado pelos entrevistados quando citam que é só via educação que é possível "ser alguém", "subir na vida", "ter estudo", "ser doutor", entre outras afirmações manifestas ou latentes que deixam essa ideia transparecer, como apresentado por Diana:

Eu sempre falo que eu tenho o fundamental, mas aí eu num queria eu tinha precon... vergonha de fala que eu tinha feito só a sexta série, quinta né num terminei a sexta. Nossa, aí eu ficava muito, assim sabe? Sabe quando tinha que faze, que você tinha que mostra que você estudo, aí eu... nossa era difícil pra mim, era não, é. Aí eu [pausa] a única coisa que tinha era isso mesmo, eu sempre falava que tinha o que eu num tinha né, que é o fundamental, o médio. Às vezes, eu até falava que tinha o médio, coisa que eu não tinha por causa de vergonha, preconceito mesmo né, que você tem de fala aquilo que você é. Então acho que é isso.

Acredita-se na possibilidade de se alcançar uma formação descrita por Adorno, desde que haja, além do esforço individual, principalmente uma mudança na estrutura cultural que tencione a relação indivíduo/sociedade e possibilite novos processos de formação individual e social. Além disso, é essencial que se repense os modelos educacionais propostos, pois muitas das vezes os conteúdos escolares apresentam-se extremamente distantes das realidades cotidianas vivenciadas pelos alunos. Dessa maneira, a formação cultural poderá ocorrer a partir do momento que o indivíduo "abrir" o espírito e se apropriar de maneira autônoma da cultura, ao invés de apenas aprender o que é imposto.

Em relação à responsabilidade pela formação, esta abrange, além do aluno e das questões pedagógicas, a figura do professor que é essencial no processo de transmissão de conhecimento e, principalmente, sua consciência crítica influenciará diretamente os alunos; o professor deveria ter consciência, ao invés de imitar o considerado culto. Diante disso, pode-se considerar que muitos professores propagam o que consideram culto sem refletir a respeito de sua função como educador e, como pessoa, isso pode ser exemplificado por meio de uma situação observada em um plantão de dúvidas de português na instituição de ensino a distância, quando o professor fala sobre narração:

[...] o professor começou a falar sobre narração, entretanto, o que foi dito foram mais dicas de o que fazer no dia do exame final, do que fundamentos da narração, a impressão foi de que o professor passava macetes para a prova final, e não ensinava elementos narrativos de fato. Eram ditas frases como, por exemplo, "Na prova, o que é importante? É importante que vocês não fujam do tema proposto, porque, assim, quando o examinador for ler, se tiver erros de português ele até releva, mas é importante ter estética, parágrafos, espaços. Por exemplo: a redação pode até estar muito boa, mas se não tiver espaços, já perde ponto e o contrário também, a redação nem tão boa, mas organizada esteticamente, dá pontos" (sic) (Anotações de Diário de Campo). 
Diante dessa situação, verifica-se a mecanização da educação, ou seja, sua transformação em instrumento de ajustamento e adaptação do indivíduo ao corpo social, características essas propagadas mecanicamente pelo professor que valida o imediatismo citado por Adorno. Além disso, pensando no vínculo professor/aluno, nota-se que muitas vezes há deficiências nesse quesito tanto para os professores quanto para os alunos, o que dificulta a vinculação entre os sujeitos e uma educação reflexiva. Por fim, consideramos que a educação ainda precisa ser muito melhorada e repensada para possibilitar a formação cultural, deixando de servir de modelagem de pessoas e a mera transmissão de conhecimentos. Portanto, faz-se necessário que a educação esteja voltada para a produção de uma consciência verdadeira; e essa é uma exigência política, pois só é possível uma democracia efetiva se os indivíduos da sociedade forem emancipados, autorreflexivos e conscientes de seus papéis sociais. Entretanto, acredita-se que o fato de a educação brasileira possibilitar o acesso para todos já é um passo em direção a novas possibilidades de esclarecimento. O que não se pode fazer é fechar os olhos para as problematizações possíveis, como a evasão escolar, pois isso levaria ao enrijecimento, à institucionalização e à adaptação irrefletida de indivíduos a uma sociedade excludente, uma vez que o acesso pode ser para todos, mas a permanência no processo escolar ainda é um problema para muitos brasileiros.

Quanto à questão de adaptação, Adorno (1995) ressalta que esta é necessária, visto que os homens precisam dela para se orientarem no mundo. Entretanto, não deve ser disseminada pela educação no sentido estrito de produzir pessoas bem ajustadas, mas sim para a consciência crítica. Contudo, "não se deve esquecer que a chave da transformação decisiva reside na sociedade e em sua relação com a escola. [...] Enquanto a sociedade gerar barbárie a partir de si mesma, a escola tem apenas condições mínimas de resistir a isto" (Adorno, 1995, p. 116).

Perante o discutido, foi possível notar que os alunos expressam em suas falas a desvalorização que atribuíam à educação quando criança e a constatação da maneira como a evasão escolar os afetou em suas vidas, pessoais e profissionais. Além disso, foi possível observar que hoje valorizam a educação pelo fato de ser essencial, principalmente, para o mercado de trabalho, fato este expresso nas falas de todos os entrevistados, bem como o arrependimento por terem parado de estudar.

Outro aspecto interessante em suas falas é a função do mercado de trabalho e da inserção no mundo do capital. Percebe-se que o mesmo mercado de trabalho que tirou as crianças da escola, para cuidarem de sua subsistência e de suas famílias, exige agora um retorno do adulto trabalhador aos bancos escolares, para que este possa continuar na cadeia produtiva e superar (ao menos ilusoriamente) sua atual situação socioeconômica. Assim, observando o discutido, considera-se a herança histórica da produção do abandono escolar presente na fala de nossos entrevistados, na qual os que vêm de classes mais pobres carregam estigmas de uma suposta lacuna cultural instaurada pelo desenvolvimento de teorias a respeito do fracasso escolar e da tendência elitista da educação, que, mesmo atualmente visando à democratização, ainda carrega vestígios da exclusão e preconceito. 
Desta forma, podemos considerar que a educação possui histórico de desvalorização por parte das políticas públicas, uma vez que, como observado na literatura, houve constantes mudanças nas políticas educacionais, que foram acompanhadas de alterações de pontos de vistas e destituição do que ocorria na política anterior. Esta questão nos leva a refletir na possibilidade da educação enfrentar o caos em que vive atualmente pelo fato de consecutivas mudanças de objetivos, e pela pseudoideia de igualdade entre as classes sociais ao acesso educacional, o que foi herdado da tradição elitista e excludente da educação, que nivelava e continua nivelando os alunos ante uma perspectiva de aluno ideal, que seria oriundo da elite/classe média, e não os reais alunos, que são ainda intitulados, por um imaginário, de menos capazes, em decorrência da "carência cultural", da situação de pobreza e de viverem em famílias "desestruturadas".

É interessante notar que o imaginário social, de que só são valorizados aqueles que detêm o conhecimento, leva os que não o têm a uma falsa concepção de que são menos humanos ou dignos de reconhecimento por parte do social. Com isso, há uma desvalorização de si, imagem esta que só é desfeita quando se volta à educação, pois desta forma o indivíduo passa a ser visto pelo outro e por si mesmo, como pertencente à sociedade. Considera-se também que a escola e educadores precisam ampliar seus olhares, seja para a educação de crianças ou de adultos. É necessário olhar o todo, indivíduo, escola, métodos de ensino, relações intra e extraescolares etc., para que desta forma compreenda-se a dinâmica do indivíduo e do meio em que está inserido e crie a possibilidade não somente para uma educação tecnicista que só prepara para o mercado de trabalho, mas também para uma reflexão emancipadora que aponte o caminho para o indivíduo na construção de uma sociedade mais justa. Em uma educação emancipatória, indivíduo e sociedade permanecem tensionados, e o sujeito possui consciência do que ocorre consigo e assim é capaz de reflexão e de autocrítica, o que possibilitaria o desenvolvimento da capacidade de amar (se relacionar genuinamente) e identificação com o outro, levando, consequentemente, à formação cultural.

Desta forma, a presente pesquisa possibilitou aos alunos e alunas entrevistados expressarem suas concepções a respeito da educação e seu retorno para escola. Assim, a maior contribuição desta pesquisa foi permitir a reflexão a respeito da educação de jovens e de adultos, uma vez que esta é pouco olhada, e os indivíduos que passam por ela e que muitas vezes trazem consigo sofrimentos psíquicos e marcas do fracasso da infância, não são ouvidos e com isto são desprovidos da possibilidade de pensarem a respeito de sua história de vida e de elaborarem seu passado, seja ressignificando-o ou apagando-o da memória. Deste modo, é o olhar para cada indivíduo em relação com a sociedade que possibilita a reflexão sobre sua realidade, bem como a identificação com o outro, o que conduz a capacidade de amar.

A fim de reverter-se a atual situação da educação, que acumula evasões, fracassos e constantes manifestações de violência, seria necessário a problematização das situações educacionais. No caso específico deste trabalho, a possibilidade de se repensar as 
histórias de vida dos alunos e alunas e suas ressignificações educacionais, bem como um olhar histórico e crítico a respeito das diversas variáveis que perpassam a educação, o que possibilitaria a reflexão diante das diretrizes da EJA e políticas públicas educacionais do nosso país. Por fim, cabe ressaltar que ainda são necessários muitos estudos no que concerne à Educação de Jovens e Adultos, pois ainda temos muitos adultos analfabetos e poucos estudos com olhar voltado a essa população e a sua história de vida.

\section{Referências}

Acosta, A. J., \& Rego, M. A. S.(2006). A Educação no decorrer da inserção do Brasil no contexto capitalista 1930-1964: Implicações na Educação de Jovens e Adultos. In M. F., Scheibel \& S. Lehenbauer (Orgs.). Reflexões sobre a Educação de Jovens e Adultos (pp. 75-92). Porto Alegre: Pallotti.

Adorno, T. W. (1995). Educação e Emancipação (4a ed.). Rio de Janeiro: Paz e Terra.

Adorno, T. W. (1996, dezembro). Teoria da Semicultura. Educação \& Sociedade, São Paulo, ano XVII, (56), 388-411. Recuperado em 26 agosto, 2016, de http://adorno. planetaclix.pt/tadorno.htm.

Asbahr, F. da S. F., \& Lopes, J. S. (2006). A culpa é sua. Psicologia USP, São Paulo, 17(1), 53-73, Recuperado em 26 agosto, 2016, de http://www.scielo.br/scielo. php?script=sci_arttext \&pid=S0103-65642006000100005\&lng=pt.

Baquero, F. G. (2001). O fracasso escolar de jovens e adultos e o imaginário social. Dissertação de mestrado em Psicologia, Universidade Católica de Brasília, Brasília. Recuperado em 26 agosto, 2016, de http://www.ucb.br/sites/100/165/TeseseDissertacoes/Ofracassoescolardejovenseadultoseoimagin.pdf.

Bardin, L. (2000). Análise de Conteúdo. (Luís Antero Reto e Augusto Pinheiro, Trads.). Lisboa: Edições 70.

Brasil. Lei de Diretrizes e Bases da Educação Nacional. Lei n. 9.394, de 20 de dezembro de 1996. (1996). Recuperado em 10 janeiro, 2014, de http://www.planalto. gov.br/ccivil_03/leis/l9394.htm.

Brasil. Ministério da Educação (2001). Educação para Jovens e Adultos: ensino fundamental proposta curricular - $1^{\circ}$ segmento (3a ed.). São Paulo/Brasília: Ação Educativa. Recuperado em 26 agosto, 2016, de http://portal.mec.gov.br/secad/ arquivos/pdf/eja/propostacurricular/primeirosegmento/propostacurricular.pdf.

Brasil. Ministério da Educação (2002). Proposta curricular para a Educação de Jovens e Adultos: segundo segmento do ensino fundamental: $5^{a}$ a $8^{a}$ série: introdução (v. 1). Brasília: Secretaria de Educação Fundamental. Recuperado em 24 dezembro, 2008, de http://portal.mec.gov.br/secad/arquivos/pdf/eja_livro_01.pdf. 
Brasil. Ministério da Educação; Instituto Nacional de Estudos e Pesquisas Educacionais Anísio Teixeira (INEP). (2013). Censo escolar da Educação Básica 2013. Brasília. Recuperado em 11 março, 2014, de http://portal.inep.gov.br/basica-censo.

Caldas, R. F. L. (2005, junho). Fracasso escolar: reflexões sobre uma história antiga, mas atual. Psicologia: Teoria e Prática. São Paulo, 7(1), 21-33. Recuperado em 26 agosto, 2016, de http://editorarevistas.mackenzie.br/index.php/ptp/article/view/ $1024 / 741$.

Collares, C. A. L., \& Moysés, M. A. A. (1997). O profissional de saúde e o fracasso escolar: compassos e descompassos. In A. M. Machado, C. Bertual, C. A. L Collares, C. B. Nora, J. G. S Bueno, \& J. L. Crochík. Conselho Regional de Psicologia de São Paulo. Educação Especial em Debate (pp.137-158). São Paulo: Casa do Psicólogo.

Crochík, J. L. (1997). Aspectos que permitem a segregação na escola pública. In Conselho Regional de Psicologia de São Paulo. Educação Especial em Debate (p. 13-22). São Paulo: Casa do Psicólogo.

Crochík, J. L. (2009). Educação para a resistência contra a barbárie. Revista Educação: Especial Biblioteca do Professor - Adorno Pensa a Educação 10, 16-25.

Ferreira, M. C., Assmar, E. M. L., Omar, A. G., Delgado, H. U., González, A. T., Silva, J. M. B., Souza, M. A., \& Cisne, M. C. F. (2002). Atribuição de Causalidade ao Sucesso e Fracasso Escolar: Um Estudo Transcultural Brasil-Argentina-México. Psicologia: Reflexão e Crítica, Porto Alegre, 15(3), 515-527, 2002. Recuperado em 12 setembro, 2014, de <http://www.scielo.br/scielo.php?script=sci_arttext\&pid= S010279722002000300006\&lng=en\&nrm=iso>.

Freire, P. (2006). Pedagogia do Oprimido. São Paulo: Paz e Terra.

Paiva, J. M. de. (2007). Educação Jesuíta no Brasil Colonial. In E. M. T. Lopes, L. M. F. Filho, \& C. G. Veiga (Orgs.). 500 anos de Educação no Brasil (pp. 43-59). Belo Horizonte: Autêntica.

Patto, M. H. S. (2005). A Produção do Fracasso Escolar: Histórias de Submissão e Rebeldia (2a ed.). São Paulo: Casa do Psicólogo.

Pereira, J. M. M. (2011/2012). A escola do riso e do esquecimento: Idosos na educação de jovens e adultos. Educ. foco, Juiz de Fora, 16(2), 11-38, set. 2011/fev. 2012.

Vargas, P. G., \& Gomes, M. de F. C. (2013). Aprendizagem e desenvolvimento de jovens e adultos: novas práticas sociais, novos sentidos. Educação e Pesquisa, 39(2), 449-463, abr./jun. 2013.

Submissão: 27.5.2015

Aceitação: 21.3.2016 